\title{
Pulmonary Rehabilitation: The Reference Therapy for Undernourished Patients with Chronic Obstructive Pulmonary Disease
}

\author{
Nikolaos Samaras, ${ }^{1}$ Dimitrios Samaras, ${ }^{2}$ Arnaud Chambellan, ${ }^{3}$ \\ Claude Pichard, ${ }^{2}$ and Ronan Thibault ${ }^{2}$ \\ ${ }^{1}$ Department of Internal Medicine, Rehabilitation and Geriatrics, Geneva University Hospital, Rue Gabrielle-Perret-Gentil 4, \\ 1211 Geneva 14, Switzerland \\ ${ }^{2}$ Nutrition Unit, Geneva University Hospital, Rue Gabrielle-Perret-Gentil 4, 1211 Geneva 14, Switzerland \\ ${ }^{3}$ Explorations Fonctionnelles, Hôpital G et R Laennec, Boulevard Jacques Monod, 44093 Nantes Cedex 1, France
}

Correspondence should be addressed to Ronan Thibault; ronan.thibault@orange.fr

Received 18 October 2013; Revised 7 January 2014; Accepted 16 January 2014; Published 19 February 2014

Academic Editor: Wim Janssens

Copyright (c) 2014 Nikolaos Samaras et al. This is an open access article distributed under the Creative Commons Attribution License, which permits unrestricted use, distribution, and reproduction in any medium, provided the original work is properly cited.

\begin{abstract}
Chronic obstructive pulmonary disease (COPD) combines the deleterious effects of chronic hypoxia, chronic inflammation, insulin-resistance, increased energy expenditure, muscle wasting, and exercise deconditioning. As for other chronic disorders, loss of fat-free mass decreased survival. The preservation of muscle mass and function, through the protection of the mitochondrial oxidative metabolism, is an important challenge in the management of COPD patients. As the prevalence of the disease is increasing and the medical advances make COPD patients live longer, the prevalence of COPD-associated nutritional disorders is expected to increase in future decades. Androgenopenia is observed in $40 \%$ of COPD patients. Due to the stimulating effects of androgens on muscle anabolism, androgenopenia favors loss of muscle mass. Studies have shown that androgen substitution could improve muscle mass in COPD patients, but alone, was insufficient to improve lung function. Two multicentric randomized clinical trials have shown that the association of androgen therapy with physical exercise and oral nutritional supplements containing omega-3 polyinsaturated fatty acids, during at least three months, is associated with an improved clinical outcome and survival. These approaches are optimized in the field of pulmonary rehabilitation which is the reference therapy of COPD-associated undernutrition.
\end{abstract}

\section{Introduction}

The natural history of COPD is poorly understood. It is commonly assumed that chronic bronchial inflammation and small airway narrowing secondary to tobacco smoke take place for many years before any obstructive ventilatory defect could be detected [1]. The main and most serious symptom reported by COPD is dyspnea as a consequence of the mechanical constraints of the obstructive ventilatory defect, which increase during exercise leading to physical inactivity and handicap [2-4]. The combined effects of systemic inflammation and tissue hypoxia partially explain several comorbidities often associated with COPD at a higher frequency than in non-COPD smokers: cardiovascular diseases, osteoporosis, diabetes, and metabolic syndrome [5].
COPD shares similar characteristics with other chronic organ insufficiencies, chronic infections, and cancer: anorexia, inflammation, insulin-resistance, hypogonadism, and anemia [6]. Moreover, increased resting energy expenditure has been reported in COPD patients [7]. These conditions are responsible for fat loss and muscle wasting [8], leading to weight loss [9], muscle weakness, and fatigue (Figure 1). COPD-related weight loss is affecting mostly muscle mass $[10,11]$ and may be found in almost $40-50 \%$ of patients at severe stages of the disease [8]. As muscle wasting is affecting skeletal as well as respiratory muscles, COPDassociated chronic undernutrition and muscle wasting lead to physical inactivity $[4,12]$, exercise deconditioning [13], and impairment of respiratory function [14], resulting in impaired 
quality of life $[4,12]$, increase in bronchial infections, general practitioner consultations [15], and reduced survival [4, 12, 16-26]. This, in turn, increases COPD-related costs (Figure 1). As the prevalence of COPD is expected to increase in future decades [27], the medicoeconomic burden of COPDassociated undernutrition will increase. The impact of undernutrition and fat-free mass loss on clinical outcome and survival is independent of respiratory parameters [16-19]. Several studies have shown that fat-free mass loss measured by bioimpedance analysis (BIA) or midthigh CT scan is a stronger predictor of mortality than body mass index [16, $20,21,24]$. Therapies aiming at specifically managing COPDassociated nutritional disorders and improving muscle mass are mandatory to reduce the negative impact of the disease on physical activity, quality of life, and clinical outcome.

\section{Physiopathology of Muscle Wasting in COPD}

As renal or chronic heart failure, the musculoskeletal system is profoundly altered in COPD patients. Muscle is characterized by decreased capillary density and a shift from the aerobic to the anaerobic glycolytic pathways: decreased diameter and smaller fraction of type I muscular fibers [29, 30] together with an increase in type II nonoxidative muscular fibers $[31,32]$ and decreased expression of aerobic glycolysis enzymes [33, 34]. These alterations are mainly related to tissue hypoxia and inflammation. Both provoke oxidative stress and stimulate the activity of the ubiquitin-proteasome pathways responsible for protein breakdown [35-38], and, in turn, muscle wasting, physical inactivity, and sedentarity. Increased protein catabolism is observed during COPD acute exacerbations [39] and during the whole course of COPD due to systemic inflammatory reaction. Protein catabolism is driven by the secretion of proinflammatory cytokines: tumor necrosis factor- $\alpha$ (TNF- $\alpha$ ), interleukin-1 (IL-1), interleukin6 (IL-6), interleukin-8 (IL-8), and interferon- $\gamma$ (INF- $\gamma$ ). The conservation of an oxidative muscle phenotype could protect myofibers from pathological insults, as shown in mice with chronic heart failure [29, 40]. Therefore the preservation of muscle mass and function, through the protection of the mitochondrial oxidative metabolism, is an important challenge in the management of COPD patients. Recent evidence suggests that pulmonary rehabilitation including physical exercise, oral nutritional supplements, and androgen therapy could improve muscle mass and function and the outcome of COPD patients [41].

\section{Evidence for Androgen Therapy in COPD}

In COPD patients, plasma concentrations of anabolic hormones, such as growth hormone $(\mathrm{GH})$ and testosterone, are frequently decreased $[38,42-45]$. A prevalence of low plasma testosterone, that is, hypogonadism, of 38\% was reported considering a cut-off of free plasma testosterone of $50 \mathrm{pg} / \mathrm{mL}$ in a group of men with severe COPD and a mean age of 70 years [43]. Others have reported a prevalence of $22 \%$ [44] and 69\% [45], which is higher than age-related hypogonadism. Indeed, total testosterone levels less than $320 \mathrm{ng} / \mathrm{dL}$ were found in $17 \%$ of patients aged between 40 and 79 years [46], and free testosterone levels less than $6.5 \mathrm{ng} / \mathrm{dL}$ were found in $32 \%$ of patients aged between 73 and 78 years [47]. In contrast to age-related hypogonadism, lower testosterone plasma concentrations in COPD are mostly associated with a decrease in luteinizing hormone (LH) and follicle stimulating hormone (FSH) hypophysis secretion [43, 48]. COPD severity and hypoxia are related to lower plasma concentrations of LH and FSH [49]. In COPD patients, one study showed an improvement in testosterone plasma concentrations after one month of oxygen therapy [50]. Chronic systemic corticosteroid treatment may alter pituitary stimulation by gonadotropin releasing hormone ( $\mathrm{GnRh})$ and thus decrease LH and testosterone synthesis and secretion [45]. Moreover, chronic inflammation, through the effects of TNF- $\alpha$ on the hypothalamus-hypophysis-gonadal axis, may participate in reducing testosterone plasma concentrations in COPD [50]. In the general population, low plasma concentrations of testosterone have been related to a decreased muscular mass [51-53] and force [51, 54, 55]. Quadriceps muscle weakness is related to low circulating levels of testosterone in men with COPD [56]. Testosterone increases muscle protein synthesis $[57,58]$, reduces adipocyte, and increases muscle cells proliferation [57]. Testosterone also inhibits leptin and stimulates ghrelin production which in its turn stimulates $\mathrm{GH}$ secretion $[11,57]$ and appetite. In addition to hypogonadism, reduced protein synthesis and muscle anabolism observed in COPD and in other chronic diseases could also be the consequence of the decrease in IGF-1 plasma concentrations, itself related to reduced $\mathrm{GH}$ secretion $[11,42,59,60]$. In patients with low plasma testosterone, androgen therapy was associated with a decrease in subcutaneous fat and an increase in muscle mass $[53,57,58,61,62]$, as well as an improvement of muscle force and functional capacities $[53,55,57,58,61-$ 66]. The rationale for androgen therapy in COPD patients is based on its ability to improve muscle mass and function [67], as well as nutritional status and clinical outcome.

\section{Androgen Therapy: Clinical Results in COPD Patients}

In COPD patients, androgen therapy has been tested alone or together with physical exercise or nutritional supplementation.

4.1. Androgen Therapy Alone. Two studies have evaluated the effect of testosterone alone, that is, not integrated in a rehabilitation program, in COPD patients $[68,69]$ (Table 1). Oral testosterone analogue oxandrolone was given in a group of 128 outpatients ( 57 men and 71 women) with GOLD II-III COPD (forced expiratory volume (FEV) $<50 \%$ ). A significant increase in fat-free mass was observed after four months of treatment [68]. However the 6-minute walking distance and spirometric data remained unchanged [68]. No differences were observed between men and women concerning treatment efficiency. Six women developed androgenic side effects (alopecia, cliteromegaly, hirsutism, and deepening of the voice) causing treatment discontinuation [68]. 


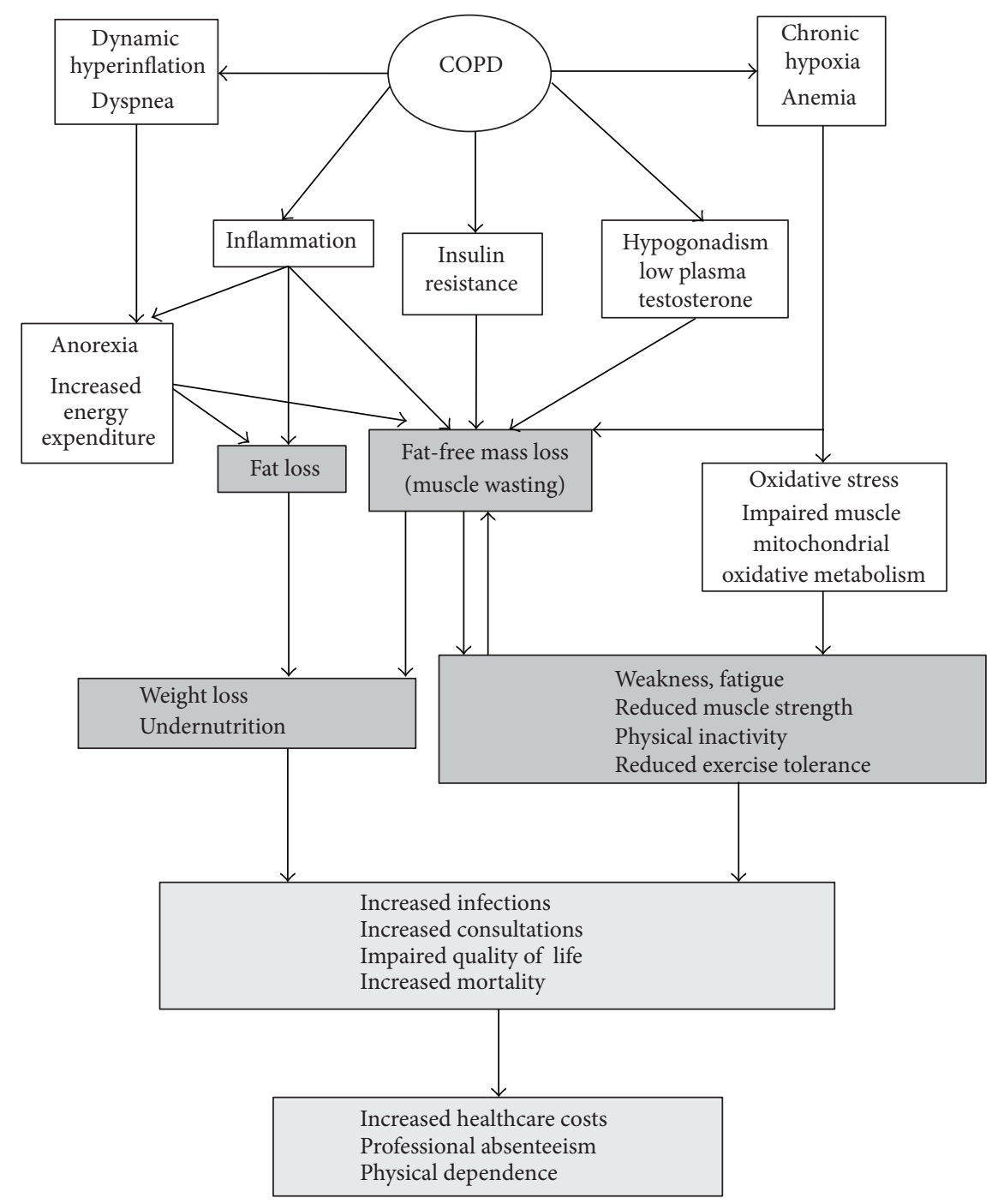

FIGURE 1: Mechanisms and clinical consequences of undernutrition in COPD patients (from [6]). The white boxes represent the metabolic mechanisms or features, and the grey boxes represent their nutritional clinical consequences. Dyspnoea is mainly attributable to dynamic hyperinflation [2]. Dynamic hyperinflation is the consequence of the loss of lung elastic recoil and increase in airway resistance, thus leading to air trapping, ventilation inefficiency, and increase in work of breathing through increase in inspiratory muscle load [28]. Dyspnoea and inflammation increase in energy expenditure and induce decreased food intake and anorexia. Other features of COPD are insulin resistance, low plasma testosterone, and chronic hypoxia associated with anemia. Altogether these conditions induce undernutrition, characterized by muscle wasting and fat loss. Chronic hypoxia and anemia are responsible for oxidative stress and impaired muscle mitochondrial oxidative metabolism. These results in weakness, fatigue, reduced muscle strength, physical inactivity, and reduced exercise tolerance, which are all favored by muscle wasting. The consequences of undernutrition are increased risk of infections, number of medical consultations, impaired quality of life, and worse survival. This worse clinical outcome has economic consequences: increases in healthcare costs, professional absenteeism, and physical dependence.

Nevertheless, testosterone supplementation was rather well tolerated in men as well as in women. In another group of 29 male outpatients with moderate to severe COPD (FEV $<60 \%$ ), intramuscular testosterone was administered for 26 weeks with positive effects on body composition: fat-free mass increased by $1.1 \mathrm{~kg}$, and fat mass decreased by $1.5 \%$ as compared to baseline. No effect was observed on lung function-associated parameters, such as blood gas analyses, spirometric data, 6-minute walking distance, and nocturnal oxygen saturation [69]. However an improvement in erectile function and sexual quality of life was reported. These two studies indicate that androgen therapy is able to improve muscle mass in COPD patients but, alone, is insufficient to improve lung function-associated parameters.

4.2. Androgen Therapy Combined with Physical Exercise. In two other studies, androgen therapy was combined with physical exercise [25, 71] (Table 1). A one-time $250 \mathrm{mg}$ intramuscular injection of testosterone at baseline, followed by daily intake of $12 \mathrm{mg}$ of oral stanozolol, was administered to ten undernourished (BMI $<20 \mathrm{~kg} / \mathrm{m}^{2}$ ) male outpatients 
TABLE 1: Clinical studies and trials having tested different protocols of androgen therapy in COPD patients.

\begin{tabular}{|c|c|c|c|c|c|c|c|c|}
\hline Study & $\begin{array}{c}\text { Drug/administration } \\
\text { route }\end{array}$ & $N$ & $\begin{array}{l}\text { GOLD } \\
\text { stage }\end{array}$ & $\begin{array}{l}\text { Fat-free mass } \\
\text { (FFM) loss }\end{array}$ & $\begin{array}{l}\text { Method of } \\
\text { FFM } \\
\text { assessment }\end{array}$ & Dose & Frequency & Duration \\
\hline $\begin{array}{l}\text { Schols et al. } \\
{[70]}\end{array}$ & $\begin{array}{c}\text { Dandrolone } \\
\text { decanoate/IM }\end{array}$ & 217 & II, III & $\begin{array}{c}\text { FFM }<67 \% \\
\text { (men) } /<63 \% \\
\text { (women) of } \\
\text { ideal weight }\end{array}$ & BIA & $\begin{array}{l}\mathrm{M}: 50 \mathrm{mg} \\
\mathrm{W}: 25 \mathrm{mg}\end{array}$ & $1 \mathrm{x} / 2$ weeks & 6 weeks \\
\hline $\begin{array}{l}\text { Ferreira et al. } \\
{[71]}\end{array}$ & $\begin{array}{l}\text { Mixture of testosterone } \\
\text { phenylpropionate, } \\
\text { isocaproate, propionate, } \\
\text { caproate/IM unique } \\
\text { dose, and then } \\
\text { stanozolol/PO }\end{array}$ & $\begin{array}{c}\text { Total }=23 \\
17 \text { completed } \\
\text { study }\end{array}$ & II, III & - & DEXA & $\begin{array}{l}\text { M: } 250 \mathrm{mg} \\
\mathrm{M}: 12 \mathrm{mg}\end{array}$ & $\begin{array}{c}\text { "Charging } \\
\text { dose" } \\
\text { 1x/day }\end{array}$ & $\begin{array}{c}\text { Unique } \\
\text { dose } \\
27 \text { weeks }\end{array}$ \\
\hline Yeh et al. [68] & Oxandrolone/PO & $\begin{array}{c}\text { Total }=128 \\
55 \text { included in } \\
4 \text {-month } \\
\text { analysis }\end{array}$ & II, III & - & BIA & $\begin{array}{l}\mathrm{M}: 10 \mathrm{mg} \\
\mathrm{W}: 10 \mathrm{mg}\end{array}$ & $\begin{array}{l}2 \mathrm{x} / \text { day } \\
2 \mathrm{x} / \text { day }\end{array}$ & 16 weeks \\
\hline $\begin{array}{l}\text { Casaburi } \\
\text { et al. [25] }\end{array}$ & $\begin{array}{l}\text { Testosterone } \\
\text { enanthate/IM }\end{array}$ & $\begin{array}{c}\text { Total }=53 \\
47 \text { completed } \\
\text { protocol }\end{array}$ & II, III, IV & - & DEXA & M: $100 \mathrm{mg}$ & 1x/week & 10 weeks \\
\hline $\begin{array}{l}\text { Pison et al. } \\
{[72]}\end{array}$ & $\begin{array}{c}\text { Testosterone } \\
\text { undecanoate/ PO }\end{array}$ & 126 & II, III, IV & $\begin{array}{c}<25 \text { th } \\
\text { percentile of } \\
\text { predicted } \\
\text { FFMI: }<18 \\
\quad \text { (men) } \\
<15 \text { (women) }\end{array}$ & BIA & $\begin{array}{l}\mathrm{M}: 80 \mathrm{mg} \\
\mathrm{W}: 40 \mathrm{mg}\end{array}$ & $\begin{array}{l}2 x / \text { day } \\
2 x / \text { day }\end{array}$ & 12 weeks \\
\hline $\begin{array}{l}\text { Svartberg } \\
\text { et al. [69] }\end{array}$ & $\begin{array}{l}\text { Testosterone } \\
\text { enanthate/IM }\end{array}$ & 29 & II, III & - & DEXA & M: $250 \mathrm{mg}$ & $1 \mathrm{x} / 4$ weeks & 26 weeks \\
\hline
\end{tabular}

BIA: bioelectrical impedance analysis; DEXA: dual energy X-ray absorptiometry; FFM: fat-free mass; FFMI: fat-free mass index (=FFM (kg)/height (m) ${ }^{2}$; IM: intramuscular; M: men; PO: per os; W: women.

with GOLD II-III COPD [71]. The control group consisted of seven patients with similar characteristics who received placebo. All patients were part of an outpatient pulmonary rehabilitation program consisting in inspiratory muscle exercises (weeks 9 to 27) and cycle ergometer exercises (weeks 18 to 27). An increase in body weight was observed in the patients receiving anabolic steroids. On the contrary, in patients receiving placebo, body weight decreased and body mass index was significantly lower at the end of the study than in the intervention group. Fat-free mass (thigh circumference, arm muscle circumference, and dual energy X-ray absorptiometry) was significantly higher in the intervention group. No differences were found in maximal inspiratory pressure or 6-minute walking distance [71]. Casaburi et al. [25] studied the effects of a 10-week intramuscular testosterone administration (100 mg of testosterone enanthate per week) with or without resistance training ( 45 minutes three times per week) in a group of 47 men with moderate to severe (GOLD II to IV) COPD (mean FEV < 60\% predicted) and low testosterone plasma concentrations $(<400 \mathrm{ng} / \mathrm{dL})$. The patients were divided in four groups: placebo without training; testosterone without training; placebo and training; testosterone and training. Only patients treated with testosterone (with or without training) reported a significant increase in fat-free mass. The group "testosterone and training" had the highest increase in muscle mass and force. This was also the only group in which significant increases in peak oxygen uptake, peak work rate, and lactic acidosis threshold were observed. A significant and similar increase in muscle force was observed in the groups "placebo and training" and "testosterone without training" [25]. These two studies indicate that the combination of testosterone and training is superior to testosterone or training alone to improve muscle mass and force.

4.3. Androgen Therapy (Testosterone) Combined with Physical Exercise and Nutritional Supplementation: Pulmonary Rehabilitation. Multimodal interventions including androgen therapy, a nutritional intervention, and an exercise program have also been assessed $[70,72]$ (Table 1). A double blind randomized trial in 217 patients with moderate to severe (GOLD II-III) COPD studied the effects of an 8-week nutritional intervention alone or combined with nandrolone decanoate IM injections every two weeks (50 mg for men and $25 \mathrm{mg}$ for women) [70]. The nutritional intervention consisted in daily adding to the regular meals one oral nutritional supplement (ONS) which was a high caloric drink $(200 \mathrm{~mL}=420 \mathrm{kcal})$ administered in the early evening between 7:00 and 9:00 p.m. Nutritional intervention lasted at least until day 57. Patients were all admitted to an intensive inpatient pulmonary rehabilitation program. Both groups (nutrition alone and nutrition + testosterone) presented with a similar weight gain. Nevertheless, those treated with the 
testosterone analogue had a significantly higher increase of fat-free mass than the placebo group. Maximal inspiratory pressure, as a measure of respiratory muscle function, significantly increased after 8 weeks only in the group treated with nandrolone [70]. No differences concerning outcomes or side effects were observed between males and females [70]. A multimodal intervention was applied in a clinical trial in a group of moderate to severe COPD outpatients consisting in endurance physical exercises combined with oral nutritional supplements and oral testosterone undecanoate administration (80 $\mathrm{mg}$ or $40 \mathrm{mg}$ twice daily for men and women, resp.) [72]. Nutritional intervention consisted ingiving three $120 \mathrm{~mL}$ ONS per day containing $180 \mathrm{kcal}$ each. This triple intervention was applied for 90 days in 60 patients with chronic respiratory failure on long-term oxygen therapy and/or noninvasive ventilation. The control group consisted of 62 patients. Patients were undernourished (body mass index < $21 \mathrm{~kg} / \mathrm{m}^{2}$ and low fat-free mass) (Table 1). In the "intervention group," positive effects were reported on muscle mass, peak workload, quadriceps isometric force, and endurance time. No effect was observed on the 6-minute walking distance. Quality of life was improved only in women, independently of respiratory status, nutritional status, or compliance to therapy. Given these results, a stronger effect of hormonal therapy in women was speculated by the authors. One year after the end of the intervention (450 days of follow-up), survival was improved in the patients compliant to the pulmonary rehabilitation. Compliance was defined as having received at least $30 \%$ of two of the three treatments (exercise, ONS, and oral testosterone undecanoate) during the 3-month intervention [72]. These two trials clearly indicate the benefits of multimodal pulmonary rehabilitation associating physical exercise, oral nutritional supplementation, and androgen therapy, on muscle mass and force and clinical outcome of COPD patients.

4.4. Pulmonary Rehabilitation: A Pivotal Therapy for COPD. As stated in recent recommendations [41, 73], pulmonary rehabilitation should now be considered as a pivotal treatment, that is, not optional, for COPD patients functionally limited by dyspnea. It has been quoted with a grade A of evidence to improve dyspnea, exercise capacity, and health status [74]. The minimal content of a pulmonary rehabilitation program is to favour the regular practice of physical activity. Physical activity is initiated through at least three-weekly supervised sessions. This has to be followed by encouragements to maintain physical activities five times a week for 30 minutes each time. This training should contain progressive muscle resistance and aerobic endurance exercises to ensure muscle strength and endurance benefits $[75,76]$. For more severely disabled patients, neuromuscular electrical stimulation could be helpful to improve muscle function [77]. Multimodal rehabilitation could be also beneficial in other chronic diseases. Specific care programs enclosing exercise training could delay the worsening of muscle atrophy in CHF patients [78, 79]. In patients with lung transplantation for respiratory chronic failure, renal failures, and type 2 diabetes, nutritional rehabilitation is
TABLE 2: Current contraindications to androgen therapy in COPD patients (from [83]).

\section{Expected survival $<6$ months}

Previous history or actual hormono-dependent cancer (prostate or breast cancer)

Prostatic nodule without any urological evaluation

International prostate symptom score (IPSS) $>19 / 35$

Prostate-specific antigen (PSA) $>4 \mathrm{ng} / \mathrm{mL}(>3 \mathrm{ng} / \mathrm{mL}$ if familial (1st degree) history of prostate cancer or if black people)

Previous history of psychotic disorders

Acute heart failure

Coronary heart disease in the past 6 months

Sleep apnea in the absence of ventilator support

Hematocrit $>50 \%$

ASAT or ALAT $>3$ times of normal values

Pulmonary artery hypertension

Neuromuscular diseases

ALAT: alanine aminotransferase; ASAT: aspartate aminotransferase.

associated with an improvement in the muscular oxidative metabolism [80-82] and a better survival [72]. The clinical trial NUTRICARD (ClinicalTrial.gov NCT01864733) is currently conducted to demonstrate whether nutritional rehabilitation would improve the clinical outcome of patients with CHF.

4.5. Safety of Androgen Therapy in COPD Patients. In the trials conducted in COPD patients and described above, androgen therapy has a safety profile. However, in these studies, androgen therapy was given during a short period of time while testosterone adverse effects appear mostly with longer treatment durations. The safety of androgen therapy has to be assessed on the long term. Extrapolating data from hypogonadic patients would be hazardous. Indeed, a significative proportion of COPD patients included in the different trials had no hypogonadism; in these patients, testosterone was used as a drug more than a hormone replacement therapy. Anyhow, physicians prescribing testosterone have to be aware of its potential side effects: cardiovascular, sleep apnea syndrome worsening, prostate cancer, and polycythemia. Androgen therapy has to be specifically monitored [84]. Contraindications to androgen therapy are known (Table 2). Patients should also be informed about adverse effects such as mastodynia, gynecomastia, acne, and infertility. The risk for polycythemia seems particularly high in patients with chronic respiratory failure [84].

\section{Perspectives}

Three-month pulmonary rehabilitation is associated with an improved survival one year after the end of therapy [72]. However, the questions of the efficacy and the safety of a long-term pulmonary rehabilitation remain. Longer studies are warranted to better judge the safety profile of testosterone 
treatment in moderate to severe COPD patients. The success of pulmonary rehabilitation is the compliance of the patients to therapy. After the end of 3-month rehabilitation, patients are strongly encouraged to go on physical activity at home. This is difficult in daily practice since patients could lack willing and encouragement. This point is crucial and deserves improving the number of caregivers specialized in the area of pulmonary rehabilitation: pneumonologists, physiotherapists, nurses, ergotherapists, ...... Research is clearly warranted to evaluate the long term effect of pulmonary rehabilitation and to determine the adapted frequency of long term physical exercise. Another important area of future research is the identification of clinical, molecular (myostatin, mitochondrial enzymes (cyclooxygenases, citrate synthase, ATPase, .....), and transcriptional factors involved in protein metabolism (mTOR, Akt, .....)) or related genetic factors involved in the clinical response to pulmonary rehabilitation. Indeed, identifying the patients who will have the best clinical benefits of pulmonary rehabilitation or androgen therapy is a key challenge.

\section{Conclusion}

Fat-free mass loss and physical inactivity are key features of COPD and are related to impaired muscular oxidative metabolism. The preservation of muscle mass and function, through the protection of the mitochondrial oxidative metabolism, is an important challenge in the management of COPD patients. Androgen therapy improves muscle mass and force but is insufficient, alone, to improve lung function and clinical outcome. Nevertheless, in undernourished COPD patients, in combination with physical training and nutritional supplementations, androgen therapy is associated with increased fat-free mass and muscle force, together with increased peak workload and endurance time, and improved survival at least one year after the end of therapy. Pulmonary rehabilitation, associating physical exercise and nutritional supplements containing omega-3 polyunsaturated fatty acids, during at least three months, is the reference therapy of undernourished COPD patients. A short-term androgen therapy (3 months) could optimize the effects of rehabilitation in selected patients. Longer studies are warranted in order to identify whether mid- or long-term pulmonary rehabilitation could further improve the clinical outcome.

\section{Conflict of Interests}

The authors declare that there is no conflict of interests regarding the publication of this paper.

\section{References}

[1] V. Kim and G. J. Criner, "Chronic bronchitis and chronic obstructive pulmonary disease," American Journal of Respiratory and Critical Care Medicine, vol. 187, no. 3, pp. 228-237, 2013.

[2] D. E. O’Donnell, R. B. Banzett, V. Carrieri-Kohlman et al., "Pathophysiology of dyspnea in chronic obstructive pulmonary disease: a roundtable," Proceedings of the American Thoracic Society, vol. 4, no. 2, pp. 145-168, 2007.
[3] D. E. O’Donnell, "Hyperinflation, dyspnea, and exercise intolerance in chronic obstructive pulmonary disease," Proceedings of the American Thoracic Society, vol. 3, no. 2, pp. 180-184, 2006.

[4] F. Pitta, T. Troosters, M. A. Spruit, V. S. Probst, M. Decramer, and R. Gosselink, "Characteristics of physical activities in daily life in chronic obstructive pulmonary disease," American Journal of Respiratory and Critical Care Medicine, vol. 171, no. 9, pp. 972-977, 2005.

[5] P. J. Barnes and B. R. Celli, "Systemic manifestations and comorbidities of COPD," European Respiratory Journal, vol. 33, no. 5, pp. 1165-1185, 2009.

[6] W. J. Evans, J. E. Morley, J. Argilés et al., "Cachexia: a new definition," Clinical Nutrition, vol. 27, no. 6, pp. 793-799, 2008.

[7] E. C. Creutzberg, A. M. W. J. Schols, F. C. M. Bothmer-Quaedvlieg, and E. F. M. Wouters, "Prevalence of an elevated resting energy expenditure in patients with chronic obstructive pulmonary disease in relation to body composition and lung function," European Journal of Clinical Nutrition, vol. 52, no. 6, pp. 396-401, 1998.

[8] A. M. W. J. Schols, P. B. Soeters, A. M. C. Dingemans, R. Mostert, P. J. Frantzen, and E. F. M. Wouters, "Prevalence and characteristics of nutritional depletion in patients with stable COPD eligible for pulmonary rehabilitation," American Review of Respiratory Disease, vol. 147, no. 5, pp. 1151-1156, 1993.

[9] M. P. K. J. Engelen, A. M. W. J. Schols, W. C. Baken, G. J. Wesseling, and E. F. M. Wouters, "Nutritional depletion in relation to respiratory and peripheral skeletal muscle function in outpatients with COPD," European Respiratory Journal, vol. 7, no. 10, pp. 1793-1797, 1994.

[10] M. P. K. J. Engelen, A. M. W. J. Schols, R. J. S. Lamers, and E. F. M. Wouters, "Different patterns of chronic tissue wasting among patients with chronic obstructive pulmonary disease," Clinical Nutrition, vol. 18, no. 5, pp. 275-280, 1999.

[11] M. I. Lewis, M. Fournier, T. W. Storer et al., "Skeletal muscle adaptations to testosterone and resistance training in men with COPD," Journal of Applied Physiology, vol. 103, no. 4, pp. 12991310, 2007.

[12] H. van Remoortel, M. Hornikx, H. Demeyer et al., "Daily physical activity in subjects with newly diagnosed COPD," Thorax, vol. 68, no. 10, pp. 962-963, 2013.

[13] P. Palange, S. Forte, A. Felli, P. Galassetti, P. Serra, and S. Carlone, "Nutritional state and exercise tolerance in patients with COPD," Chest, vol. 107, no. 5, pp. 1206-1212, 1995.

[14] Y. Nishimura, M. Tsutsumi, H. Nakata, T. Tsunenari, H. Maeda, and M. Yokoyama, "Relationship between respiratory muscle strength and lean body mass in men with COPD," Chest, vol. 107, no. 5, pp. 1232-1236, 1995.

[15] R. Thibault, E. Le Gallic, M. Picard-Kossovsky, D. Darmaun, and A. Chambellan, "Assessment of nutritional status and body composition in patients with COPD: comparison of several methods," Revue des Maladies Respiratoires, vol. 27, no. 7, pp. 693-702, 2010.

[16] A. M. W. J. Schols, J. Slangen, L. Volovics, and E. F. M. Wouters, "Weight loss is a reversible factor in the prognosis of chronic obstructive pulmonary disease," American Journal of Respiratory and Critical Care Medicine, vol. 157, no. 6, pp. 1791-1797, 1998.

[17] C. Landbo, E. Prescott, P. Lange, J. Vestbo, and T. P. Almdal, "Prognostic value of nutritional status in chronic obstructive pulmonary disease," American Journal of Respiratory and Critical Care Medicine, vol. 160, no. 6, pp. 1856-1861, 1999. 
[18] S. Marti, X. Muñoz, J. Rios, F. Morell, and J. J. Ferrer, "Body weight and comorbidity predict mortality in COPD patients treated with oxygen therapy," European Respiratory Journal, vol. 27, no. 4, pp. 689-696, 2006.

[19] K. Gray-Donald, L. Gibbons, S. H. Shapiro, P. T. Macklem, and J. G. Martin, "Nutritional status and mortality in chronic obstructive pulmonary disease," American Journal of Respiratory and Critical Care Medicine, vol. 153, no. 3, pp. 961-966, 1996.

[20] K. Marquis, R. Debigaré, Y. Lacasse et al., "Midthigh muscle cross-sectional area is a better predictor of mortality than body mass index in patients with chronic obstructive pulmonary disease," American Journal of Respiratory and Critical Care Medicine, vol. 166, no. 6, pp. 809-813, 2002.

[21] F. Slinde, A. M. Grönberg, C.-P. Engström, L. Rossander-Hulthén, and S. Larsson, "Body composition by bioelectrical impedance predicts mortality in chronic obstructive pulmonary disease patients," Respiratory Medicine, vol. 99, no. 8, pp. 10041009, 2005.

[22] E. Chailleux, J.-P. Laaban, and D. Veale, "Prognostic value of nutritional depletion in patients with COPD treated by longterm oxygen therapy: data from the ANTADIR observatory," Chest, vol. 123, no. 5, pp. 1460-1466, 2003.

[23] N. J. M. Cano, C. Pichard, H. Roth et al., "C-reactive protein and body mass index predict outcome in end-stage respiratory failure," Chest, vol. 126, no. 2, pp. 540-546, 2004.

[24] A. M. W. J. Schols, R. Broekhuizen, C. A. Weling-Scheepers, and E. F. Wouters, "Body composition and mortality in chronic obstructive pulmonary disease," American Journal of Clinical Nutrition, vol. 82, no. 1, pp. 53-59, 2005.

[25] R. Casaburi, S. Bhasin, L. Cosentino et al., "Effects of testosterone and resistance training in men with chronic obstructive pulmonary disease," American Journal of Respiratory and Critical Care Medicine, vol. 170, no. 8, pp. 870-878, 2004.

[26] J. Svartberg, "Androgens and chronic obstructive pulmonary disease," Current Opinion in Endocrinology, Diabetes and Obesity, vol. 17, no. 3, pp. 257-261, 2010.

[27] A. Jemal, E. Ward, Y. Hao, and M. Thun, "Trends in the leading causes of death in the United States, 1970-2002," Journal of the American Medical Association, vol. 294, no. 10, pp. 1255-1259, 2005.

[28] D. E. O’Donnell, J. C. Bertley, L. K. L. Chau, and K. A. Webb, "Qualitative aspects of exertional breathlessness in chronic airflow limitation: pathophysiologic mechanisms," American Journal of Respiratory and Critical Care Medicine, vol. 155, no. 1, pp. 109-115, 1997.

[29] T. Geng, P. Li, X. Yin, and Z. Yan, "PGC-1 $\alpha$ promotes nitric oxide antioxidant defenses and inhibits FOXO signaling against cardiac cachexia in mice," American Journal of Pathology, vol. 178, no. 4, pp. 1738-1748, 2011.

[30] J. Jobin, F. Maltais, J.-F. Doyon et al., "Chronic obstructive pulmonary disease: capillarity and fiber-type characteristics of skeletal muscle," Journal of Cardiopulmonary Rehabilitation, vol. 18, no. 6 , pp. 432-437, 1998.

[31] H. Drexler, U. Riede, T. Munzel, H. Konig, E. Funke, and H. Just, "Alterations of skeletal muscle in chronic heart failure," Circulation, vol. 85, no. 5, pp. 1751-1759, 1992.

[32] D. P. Lipkin, D. A. Jones, J. M. Round, and P. A. Poole-Wilson, "Abnormalities of skeletal muscle in patients with chronic heart failure," International Journal of Cardiology, vol. 18, no. 2, pp. 187-195, 1988.

[33] F. Maltais, A.-A. Simard, C. Simard et al., "Oxidative capacity of the skeletal muscle and lactic acid kinetics during exercise in normal subjects and in patients with COPD," American Journal of Respiratory and Critical Care Medicine, vol. 153, no. 1, pp. 288293, 1996.

[34] J. Sauleda, F. García-Palmer, R. J. Wiesner et al., "Cytochrome oxidase activity and mitochondrial gene expression in skeletal muscle of patients with chronic obstructive pulmonary disease," American Journal of Respiratory and Critical Care Medicine, vol. 157, no. 5, part 1, pp. 1413-1417, 1998.

[35] C. A. Raguso and C. Luthy, "Nutritional status in chronic obstructive pulmonary disease: role of hypoxia," Nutrition, vol. 27, no. 2, pp. 138-143, 2011.

[36] M. A. Dentener, E. C. Creutzberg, A. M. W. J. Schols et al., "Systemic anti-inflammatory mediators in COPD: increase in soluble interleukin 1 receptor II during treatment of exacerbations," Thorax, vol. 56, no. 9, pp. 721-726, 2001.

[37] A. A. Eid, A. A. Ionescu, L. S. Nixon et al., "Inflammatory response and body composition in chronic obstructive pulmonary disease," American Journal of Respiratory and Critical Care Medicine, vol. 164, no. 8 I, pp. 1414-1418, 2001.

[38] R. Debigaré, C. H. Côté, and F. Maltais, "Peripheral muscle wasting in chronic obstructive pulmonary disease: clinical relevance and mechanisms," American Journal of Respiratory and Critical Care Medicine, vol. 164, no. 9, pp. 1712-1717, 2001.

[39] M. A. P. Vermeeren, A. M. W. J. Schols, and E. F. M. Wouters, "Effects of an acute exacerbation on nutritional and metabolic profile of patients with COPD," European Respiratory Journal, vol. 10, no. 10, pp. 2264-2269, 1997.

[40] P. Li, R. E. Waters, S. I. Redfern et al., "Oxidative phenotype protects myofibers from pathological insults induced by chronic heart failure in mice," American Journal of Pathology, vol. 170, no. 2, pp. 599-608, 2007.

[41] M. A. Spruit, S. J. Singh, C. Garvey et al., "An official American Thoracic Society/European Respiratory Society statement: key concepts and advances in pulmonary rehabilitation," American Journal of Respiratory and Critical Care Medicine, vol. 188, no. 8, pp. e13-e64, 2013.

[42] E. C. Creutzberg and R. Casaburi, "Endocrinological disturbances in chronic obstructive pulmonary disease," European Respiratory Journal, Supplement, vol. 22, no. 46, pp. 76s-80s, 2003.

[43] F. Laghi, A. Antonescu-Turcu, E. Collins et al., "Hypogonadism in men with chronic obstructive pulmonary disease: prevalence and quality of life," American Journal of Respiratory and Critical Care Medicine, vol. 171, no. 7, pp. 728-733, 2005.

[44] R. Debigaré, K. Marquis, C. H. Côté et al., "Catabolic/anabolic balance and muscle wasting in patients with COPD," Chest, vol. 124, no. 1, pp. 83-89, 2003.

[45] A. Kamischke, D. E. Kemper, M. A. Castel et al., "Testosterone levels in men with chronic obstructive pulmonary disease with or without glucocorticoid therapy," European Respiratory Journal, vol. 11, no. 1, pp. 41-45, 1998.

[46] F. C. W. Wu, A. Tajar, J. M. Beynon et al., "Identification of lateonset hypogonadism in middle-aged and elderly men," The New England Journal of Medicine, vol. 363, no. 2, pp. 123-135, 2010.

[47] B. Lapauw, S. Goemaere, H. Zmierczak et al., "The decline of serum testosterone levels in community-dwelling men over 70 years of age: descriptive data and predictors of longitudinal changes," European Journal of Endocrinology, vol. 159, no. 4, pp. 459-468, 2008.

[48] N. Samaras, D. Samaras, P. O. Lang et al., "A view of geriatrics through hormones," Maturitas, 2012. 
[49] U. Aasebo, A. Gyltnes, R. M. Bremnes, A. Aakvaag, and L. Slordal, "Reversal of sexual impotence in male patients with chronic obstructive pulmonary disease and hypoxemia with long term oxygen therapy," Journal of Steroid Biochemistry and Molecular Biology, vol. 46, no. 6, pp. 799-803, 1993.

[50] T. van der Poll, J. A. Romijn, E. Endert, and H. P. Sauerwein, "Effects of tumor necrosis factor on the hypothalamic-pituitarytesticular axis in healthy men," Metabolism, vol. 42, no. 3, pp. 303-307, 1993.

[51] F. R. Sattler, C. Castaneda-Sceppa, E. F. Binder et al., "Testosterone and growth hormone improve body composition and muscle performance in older men," Journal of Clinical Endocrinology and Metabolism, vol. 94, no. 6, pp. 1991-2001, 2009.

[52] C. Serra, S. Bhasin, F. Tangherlini et al., "The role of GH and IGF-I in mediating anabolic effects of testosterone on androgen-responsive muscle," Endocrinology, vol. 152, no. 1, pp. 193206, 2011.

[53] T. W. Storer, L. Woodhouse, L. Magliano et al., "Changes in muscle mass, muscle strength, and power but not physical function are related to testosterone dose in healthy older men," Journal of the American Geriatrics Society, vol. 56, no. 11, pp. 1991-1999, 2008.

[54] M. Maggio, G. P. Ceda, F. Lauretani et al., "Gonadal status and physical performance in older men," Aging Male, vol. 14, no. 1, pp. 42-47, 2011.

[55] M. D. L. O’Connell, A. Tajar, S. A. Roberts, and F. C. W. Wu, "Do androgens play any role in the physical frailty of ageing men?" International Journal of Andrology, vol. 34, no. 3, pp. 195-211, 2011.

[56] M. Van Vliet, M. A. Spruit, G. Verleden et al., "Hypogonadism, quadriceps weakness, and exercise intolerance in chronic obstructive pulmonary disease," American Journal of Respiratory and Critical Care Medicine, vol. 172, no. 9, pp. 1105-1111, 2005.

[57] Z. Hyde, P. E. Norman, L. Flicker et al., "Low free testosterone predicts mortality from cardiovascular disease but not other causes: the health in men study," Journal of Clinical Endocrinology and Metabolism, vol. 97, no. 1, pp. 179-189, 2012.

[58] M. Oettel, D. Hübler, and V. Patchev, "Selected aspects of endocrine pharmacology of the aging male," Experimental Gerontology, vol. 38, no. 1-2, pp. 189-198, 2003.

[59] S. Scalvini, "Plasma hormone levels and haemodynamics in patients with chronic obstructive lung disease," Monaldi Archives for Chest Disease, vol. 51, no. 5, pp. 380-386, 1996.

[60] A. Hjalmarsen, U. Aasebø, K. Birkeland, G. Sager, and R. Jorde, "Impaired glucose tolerance in patients with chronic hypoxic pulmonary disease," Diabetes and Metabolism, vol. 22, no. 1, pp. 37-42, 1996.

[61] U. Srinivas-Shankar, S. A. Roberts, M. J. Connolly et al., "Effects of testosterone on muscle strength, physical function, body composition, and quality of life in intermediate-frail and frail elderly men: a randomized, double-blind, placebo-controlled study," Journal of Clinical Endocrinology and Metabolism, vol. 95, no. 2, pp. 639-650, 2010.

[62] M. H. Emmelot-Vonk, H. J. J. Verhaar, H. R. Nakhai Pour et al., "Effect of testosterone supplementation on functional mobility, cognition, and other parameters in older men: a randomized controlled trial," Journal of the American Medical Association, vol. 299, no. 1, pp. 39-52, 2008.

[63] S. Basaria, A. D. Coviello, T. G. Travison et al., "Adverse events associated with testosterone administration," The New England Journal of Medicine, vol. 363, no. 2, pp. 109-122, 2010.
[64] K. J. Ottenbacher, M. E. Ottenbacher, A. J. Ottenbacher, A. A. Acha, and G. V. Ostir, "Androgen treatment and muscle strength in elderly men: a meta-analysis," Journal of the American Geriatrics Society, vol. 54, no. 11, pp. 1666-1673, 2006.

[65] T. G. Travison, S. Basaria, T. W. Storer et al., "Clinical meaningfulness of the changes in muscle performance and physical function associated with testosterone administration in older men with mobility limitation," Journals of Gerontology A, vol. 66, no. 10, pp. 1090-1099, 2011.

[66] A. B. Araujo, T. G. Travison, S. Bhasin et al., "Association between testosterone and estradiol and age-related decline in physical function in a diverse sample of men," Journal of the American Geriatrics Society, vol. 56, no. 11, pp. 2000-2008, 2008.

[67] M. S. Velema, B. H. B. Kwa, and W. De Ronde, "Should androgenic anabolic steroids be considered in the treatment regime of selected chronic obstructive pulmonary disease patients?" Current Opinion in Pulmonary Medicine, vol. 18, no. 2, pp. 118124, 2012.

[68] S.-S. Yeh, B. DeGuzman, and T. Kramer, "Reversal of COPDassociated weight loss using the anabolic agent oxandrolone," Chest, vol. 122, no. 2, pp. 421-428, 2002.

[69] J. Svartberg, U. Aaseboø, A. Hjalmarsen, J. Sundsfjord, and R. Jorde, "Testosterone treatment improves body composition and sexual function in men with COPD, in a 6-month randomized controlled trial," Respiratory Medicine, vol. 98, no. 9, pp. 906913, 2004.

[70] A. M. W. J. Schols, P. B. Soeters, R. Mostert, R. J. Pluymers, and E. F. M. Wouters, "Physiologic effects of nutritional support and anabolic steroids in patients with chronic obstructive pulmonary disease: a placebo-controlled randomized trial," American Journal of Respiratory and Critical Care Medicine, vol. 152, no. 4, part 1, pp. 1268-1274, 1995.

[71] I. M. Ferreira, I. T. Verreschi, L. E. Nery et al., "The influence of 6 months of oral anabolic steroids on body mass and respiratory muscles in undernourished COPD patients," Chest, vol. 114, no. 1, pp. 19-28, 1998.

[72] C. M. Pison, N. J. Cano, C. Chérion et al., "Multimodal nutritional rehabilitation improves clinical outcomes of malnourished patients with chronic respiratory failure: a randomised controlled trial," Thorax, vol. 66, no. 11, pp. 953-960, 2011.

[73] C. E. Bolton, E. F. Bevan-Smith, J. D. Blakey et al., "British Thoracic Society guideline on pulmonary rehabilitation in adults," Thorax, 2013.

[74] Y. Lacasse, S. Martin, T. J. Lasserson, and R. S. Goldstein, "Metaanalysis of respiratory rehabilitation in chronic obstructive pulmonary disease a Cochrane systematic review," Europa Medicophysica, vol. 43, no. 4, pp. 475-485, 2007.

[75] A. L. Ries, G. S. Bauldoff, B. W. Carlin et al., "Pulmonary rehabilitation: joint ACCP/AACVPR Evidence-Based Clinical Practice Guidelines," Chest, vol. 131, no. 5, supplement, pp. 4S-42S, 2007.

[76] I. Vogiatzis, "Strategies of muscle training in very severe COPD patients," European Respiratory Journal, vol. 38, no. 4, pp. 971975, 2011.

[77] I. Vivodtzev, J.-L. Pépin, G. Vottero et al., "Improvement in quadriceps strenght and dyspnea in daily tasks after 1 month of electrical stimulation in severely deconditioned and malnourished COPD," Chest, vol. 129, no. 6, pp. 1540-1548, 2006.

[78] S. D. Anker and A. J. S. Coats, "Cardiac cachexia: a syndrome with impaired survival and immune and neuroendocrine activation," Chest, vol. 115, no. 3, pp. 836-847, 1999. 
[79] K. Lenk, R. Schur, A. Linke et al., "Impact of exercise training on myostatin expression in the myocardium and skeletal muscle in a chronic heart failure model," European Journal of Heart Failure, vol. 11, no. 4, pp. 342-348, 2009.

[80] C. Héliès-Toussaint, C. Moinard, C. Rasmusen, I. Tabbi-Anneni, L. Cynober, and A. Grynberg, "Aortic banding in rat as a model to investigate malnutrition associated with heart failure," American Journal of Physiology, vol. 288, no. 5, pp. R1325-R1331, 2005.

[81] K. Guerrero, B. Wuyam, P. Mezin et al., "Functional coupling of adenine nucleotide translocase and mitochondrial creatine kinase is enhanced after exercise training in lung transplant skeletal muscle," American Journal of Physiology, vol. 289, no. 4, pp. R1144-R1154, 2005.

[82] E. C. H. van den Ham, J. P. Kooman, A. M. W. J. Schols et al., "The functional, metabolic, and anabolic responses to exercise training in renal transplant and hemodialysis patients," Transplantation, vol. 83, no. 8, pp. 1059-1068, 2007.

[83] N. Samaras, D. Samaras, P. O. Lang et al., "Chronic obstructive pulmonary disease: risk and benefit of testosterone therapy," Revue Médicale Suisse, vol. 8, no. 363, pp. 2224-2227, 2012.

[84] N. Samaras, E. Frangos, A. Forster, C. Graf, and D. Samaras, "Back pain: a case of ivory vertebrae and ribs," European Geriatric Medicine, vol. 3, no. 3, pp. 184-185, 2012. 


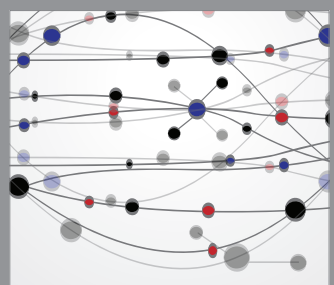

The Scientific World Journal
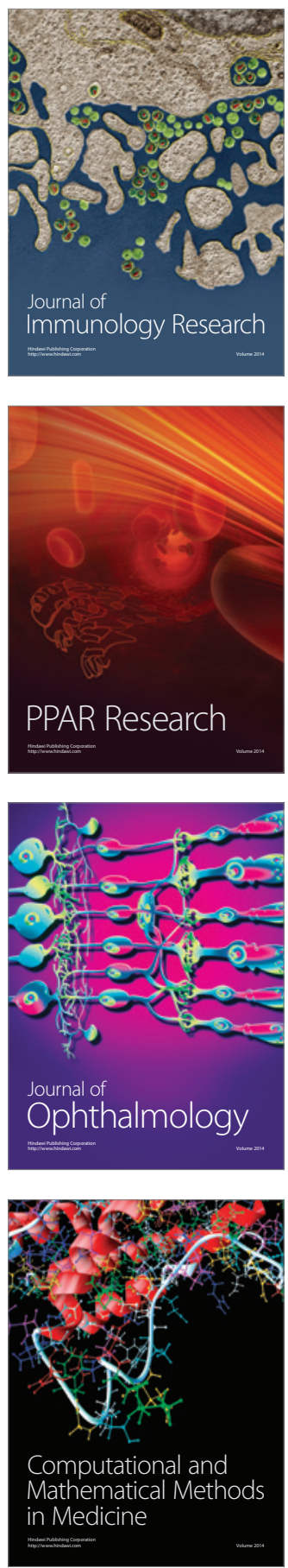

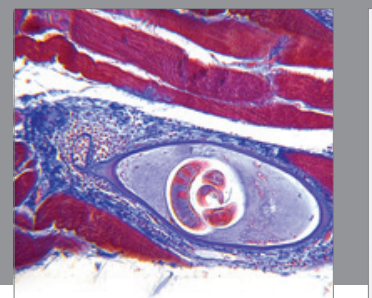

Gastroenterology

Research and Practice
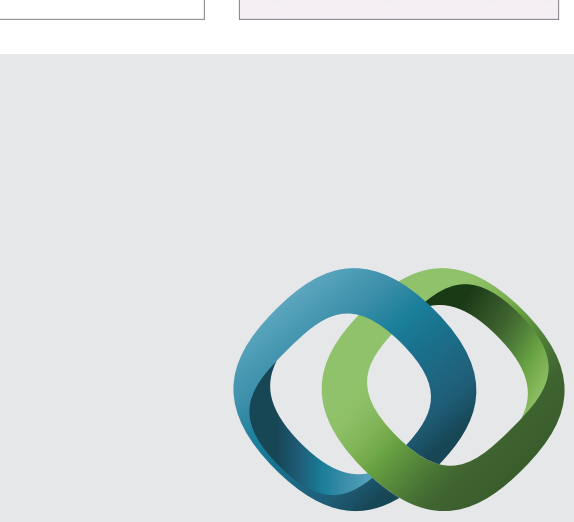

\section{Hindawi}

Submit your manuscripts at

http://www.hindawi.com
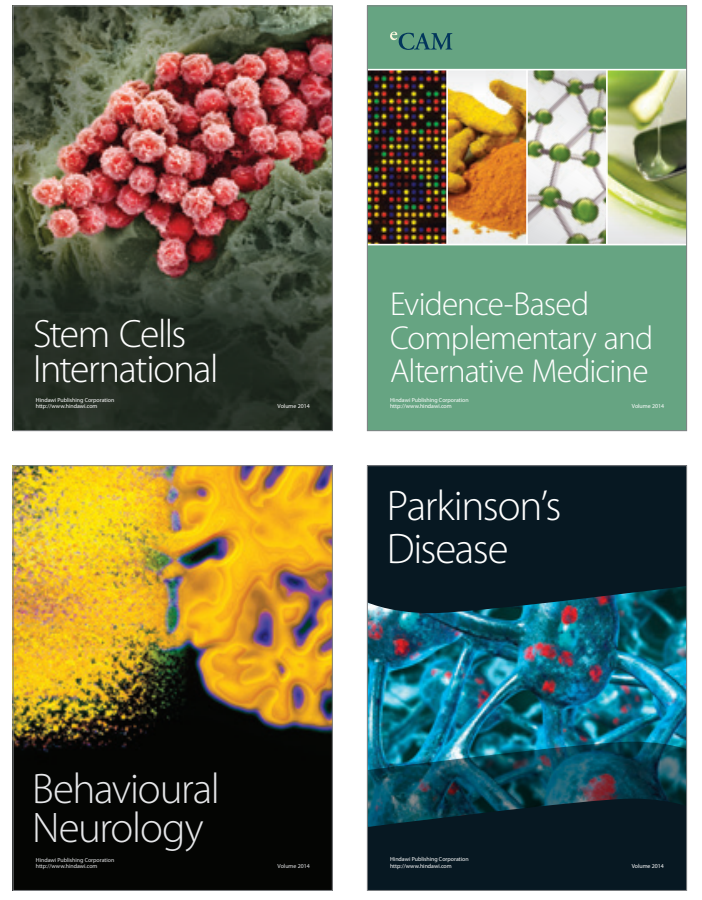
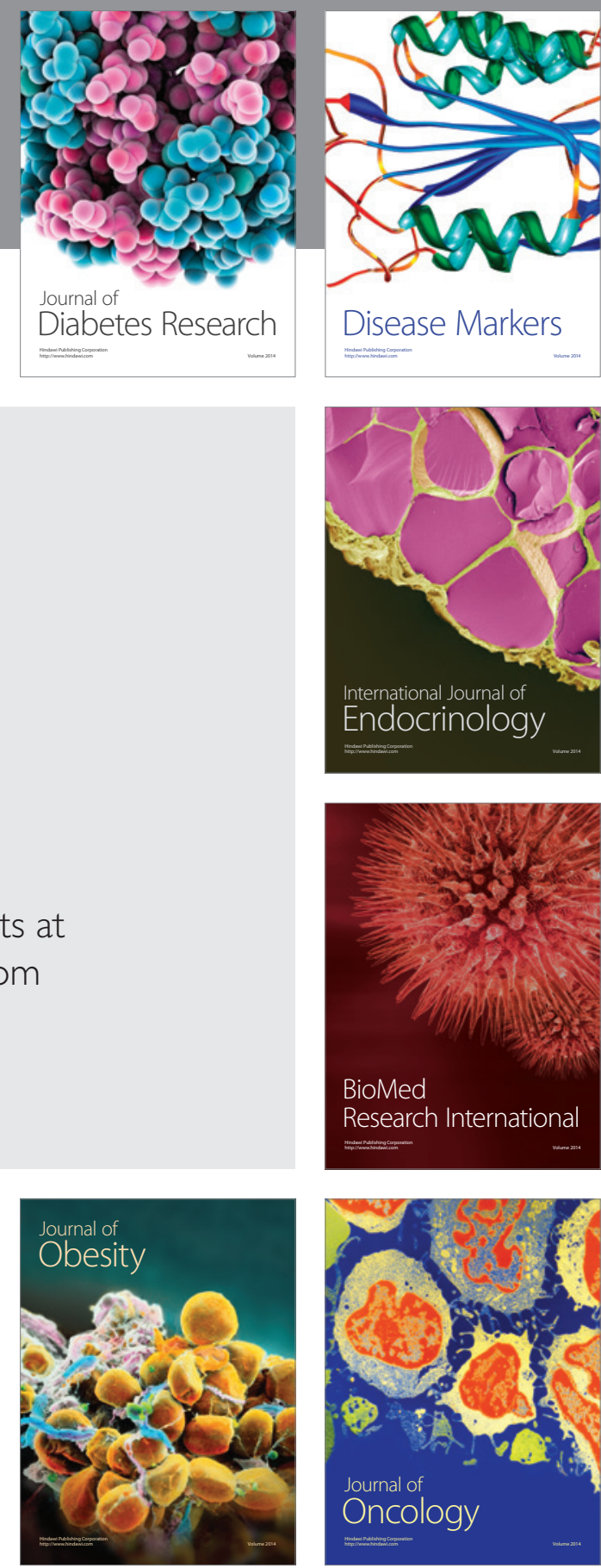

Disease Markers
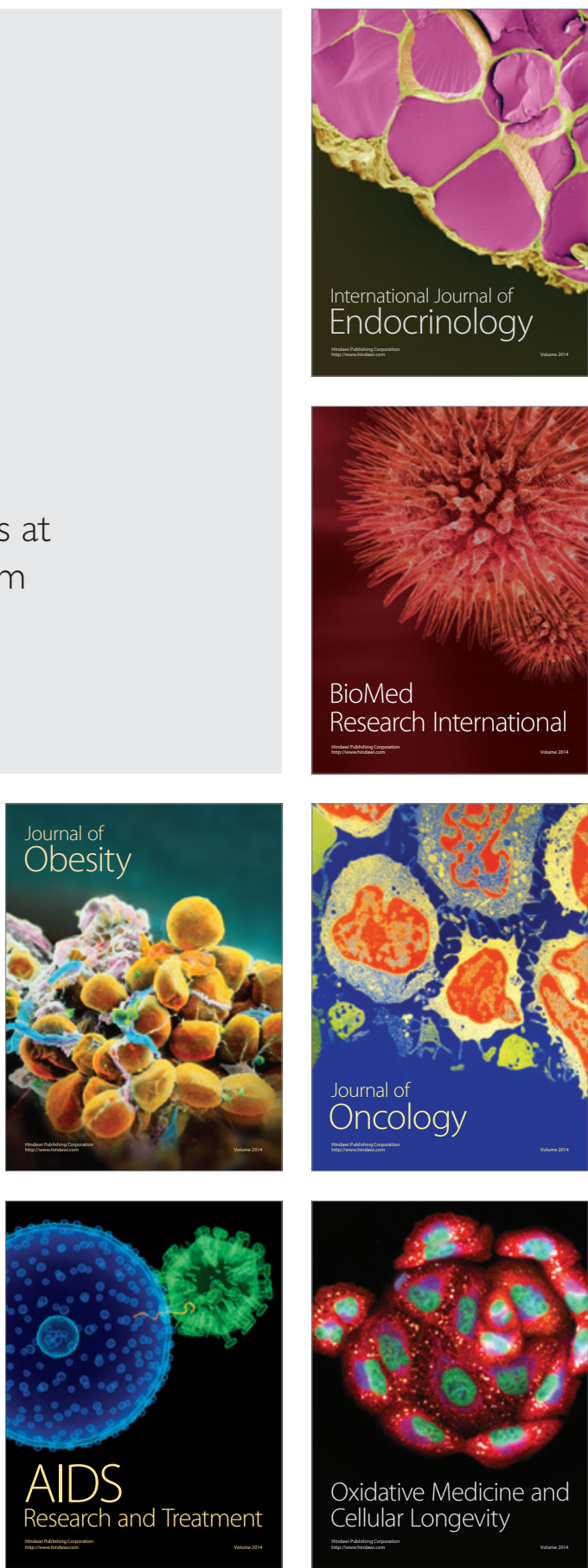